\title{
Successful detection of SRY gene via fine needle biopsy: A case of extragenital gestational choriocarcinoma in the kidney
}

\author{
SHUNSUKE ORISAKA $^{1}$, KYOSUKE KAGAMI ${ }^{1}$, YASUNARI MIZUMOTO ${ }^{1}$, \\ WATARU KODA $^{2}$, MASANORI ONO ${ }^{1}$, MITSUHIRO NAKAMURA ${ }^{1}$ and HIROSHI FUJIWARA ${ }^{1}$ \\ Departments of ${ }^{1}$ Obstetrics and Gynecology, and ${ }^{2}$ Radiology, Kanazawa University \\ Graduate School of Medical Sciences, Kanazawa, Ishikawa 920-8641, Japan
}

Received August 31, 2017; Accepted October 13, 2017

DOI: $10.3892 /$ mco.2017.1460

\begin{abstract}
The current report describes a case of extragenital gestational choriocarcinoma in the kidney. A 36-year-old woman with a history of two deliveries of male babies visited the present hospital due to secondary amenorrhea following a positive urinary pregnancy test. Despite a high serum level of human chorionic gonadotropin, at 51,800 mIU/ml, diagnostic imaging methods and pathological examination did not detect any conceptus in the genital tract. Positron emission tomography-computed tomography detected ${ }^{18}$ F-FDG-positive tumors in the left kidney and right lung. A fine needle biopsy of the renal lesion pathologically revealed the presence of choriocarcinoma and a subsequent polymerase chain reaction analysis verified the presence of a Y-chromosome-specific the sex-determining region Y (SRY) gene, diagnosed as extragenital gestational choriocarcinoma. Clinically, 10 cycles of EMA/CO chemotherapy were administered and an optimal response was obtained. In conclusion, this is the first report of the diagnosis of extragenital gestational choriocarcinoma by the detection of the SRY gene with PCR using biopsy samples.
\end{abstract}

\section{Introduction}

Choriocarcinoma is classified into two types: gestational and non-gestational (1-3). Gestational choriocarcinoma affects women at reproductive age and is derived from pregnancies including hydatidiform mole, miscarriage, ectopic pregnancy and term or pre-term deliveries $(4,5)$. Therefore, it theoretically contains paternal genes. The incidence of gestational choriocarcinoma is estimated in 1:40,000-50,000 pregnancies, and 1:40 hydatidiform mole cases. Non-gestational choriocarcinoma is independent of pregnancies and less sensitive to

Correspondence to: Dr Masanori Ono, Department of Obstetrics and Gynecology, Kanazawa University Graduate School of Medical Sciences, 13-1 Takaramachi, Kanazawa, Ishikawa 920-8641, Japan E-mail: masanori@med.kanazawa-u.ac.jp

Key words: choriocarcinoma, extragenital choriocarcinoma, needle biopsy, PCR, SRY gene chemotherapy compared to gestational choriocarcinoma (4-7). Non-gestational choriocarcinoma is reported as a very rare tumor $(4,8)$. Choriocarcinoma in the female genital tract is generally treated as the gestational type. However, when the lesion is in the extragenital organs, differential diagnosis will be difficult based on clinical data alone. Furthermore, since there is little difference in morphological characterizations on pathological examination between the two types of choriocarcinomas, gene analysis is recommended to obtain definitive diagnosis in some cases (9).

In general, a single DNA strand conformation polymorphism analysis to evaluate short tandem repeat sites is employed for gene analysis of choriocarcinoma using resected lesions following surgery. However, the reliability of this method may be reduced in cases of low amounts of tumor DNA and/or marked contamination by maternal DNA. On the other hand, when gestational carcinomas have originated from male conceptuses, we can prove the presence of paternal genes by detecting Y-chromosome-specific genes.

Based on this background, we here report a case of extragenital choriocarcinoma in the kidney that was successfully diagnosed as a gestational type by detection of the Sex-determining region Y (SRY) gene in needle-biopsied fine tissue samples. The informed consent of this report was obtained from the patient.

\section{Case report}

Five months after the second parturition, a 36-year-old woman visited a nearby hospital due to secondary amenorrhea with nausea after obtaining a positive result on a urinary pregnancy test. She had a past history of two normal vaginal deliveries of male babies 4.5 years and six months ago, respectively, and received artificial abortion one time. Although the serum level of human chorionic gonadotropin (hCG) was elevated at $51,800 \mathrm{mIU} / \mathrm{ml}$, a gestational sac was not observed in the uterus or bilateral adnexa by ultrasonography. Computed tomography (CT) and magnetic resonance imaging (MRI) did not detect a gestational sac in the genital tract, but showed abnormal solitary tumor features in the left kidney and right lung (Fig. 1A), Positron emission tomography-computed tomography (PET-CT) confirmed that both tumor lesions showed a high uptake of ${ }^{18}$ F-FDG (Fig. 1B). Pathological examination by endometrial 

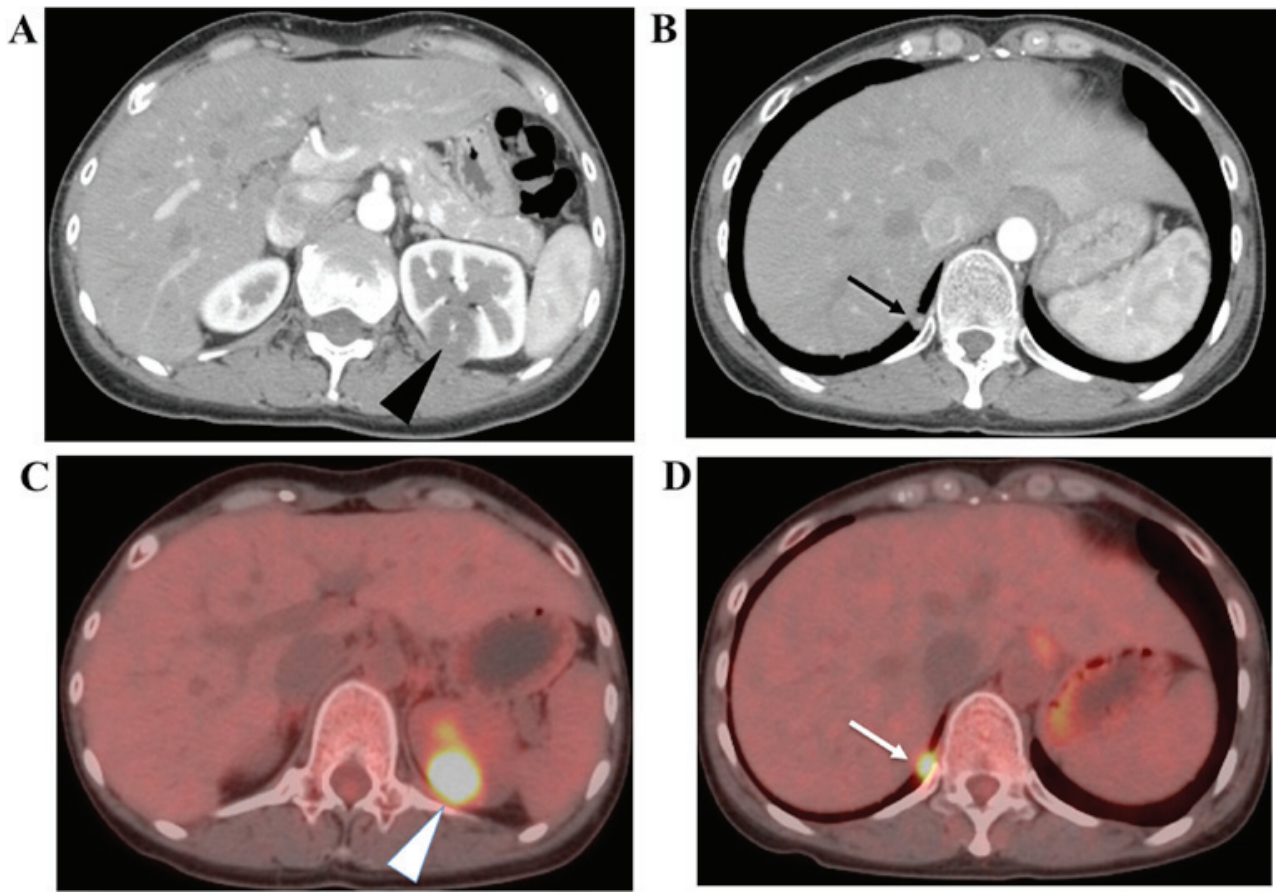

Figure 1. Enhanced CT and PET-CT images. (A and B) Enhanced CT images. (A) A slightly enhanced tumor lesion of $3.5 \mathrm{~cm}$ in its longest diameter was observed in the posterior wall of the left kidney (arrowhead). No hemorrhagic lesion was detected in the tumor. (B) A solitary lesion was observed in the posterior pleural cavity of the right lung (arrow). (C and D) PET-CT images. High uptake of ${ }^{18} \mathrm{~F}-\mathrm{FDG}$ was observed in both tumors in the kidney (arrowhead) and in the pleural cavity (arrow).

A

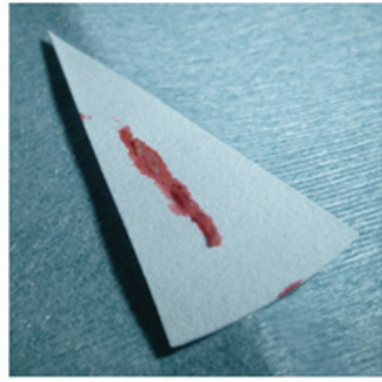

B

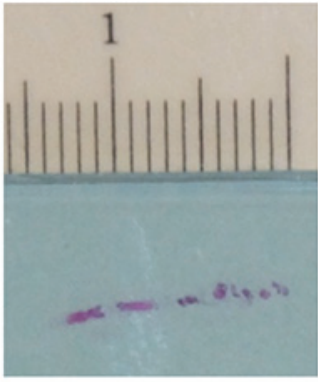

C

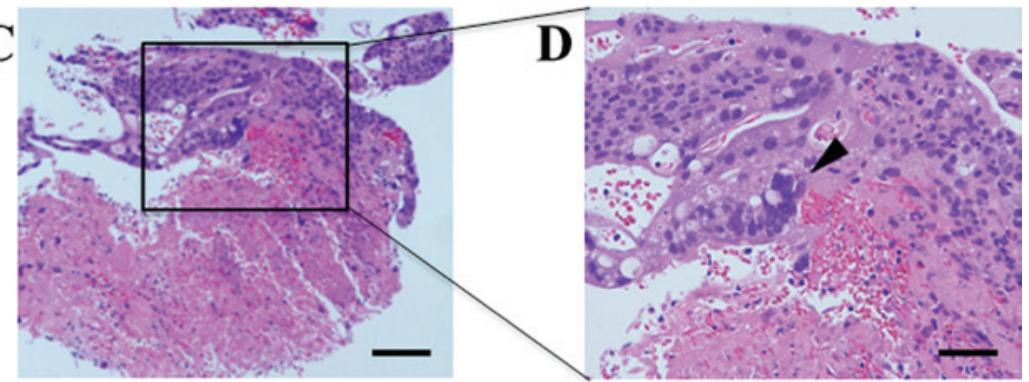

$\mathbf{E}$

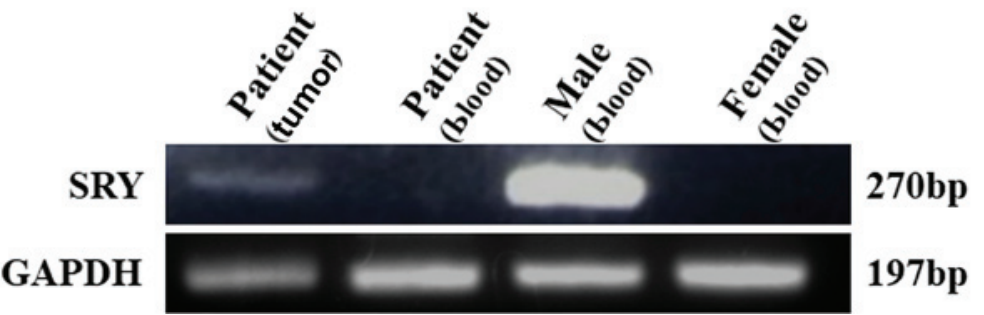

Figure 2. Analysis of a needle-biopsied sample. (A) The overall features of the needle-biopsied sample. (B) A tissue slide of the needle-biopsied sample. (C and D) Microscopic images. Atypical polynuclear giant cells resembling a syncytiotrophoblast (arrowhead) were observed without constructing chorionic villi. Bars show 100 and $50 \mu \mathrm{m}$, respectively. (E) PCR analysis of the SRY gene. PCR products of $270 \mathrm{bp}$ corresponding to the SRY gene were detected in the tumor sample and a blood sample from a male volunteer (positive control), while they were not detected in the blood samples of the patient and a female volunteer (negative control). 
curettage was negative for an intrauterine conceptus. The ultrasonographic characterization of the renal lesion suggested renal cell carcinoma. Therefore, to determine whether it was metastatic trophoblastic disease or renal cell carcinoma, we biopsied the renal lesion with a fine needle technique (Fig. 2A), and obtained a final pathological diagnosis of choriocarcinoma (Fig. 2B and C). We chose a chemotherapeutic regimen comprising etoposide, methotrexate, actinomycin-D, cyclophosphamide and vincristine (EMA/CO chemotherapy) and performed 10 courses. The serum hCG level was successfully reduced to less than $1 \mathrm{mIU} / \mathrm{ml}$. The enhanced CT confirmed the size reduction of both tumors with avascular changes. The uptake of ${ }^{18}$ F-FDG by PET-CT was also diminished. No sign of recurrence was observed during the 18-month follow-up period.

Although the serum level of hCG has been controlled under the detection limit, we could not obtain a complete response based on CT. Since non-gestational choriocarcinoma was reported to be associated with a poor prognosis $(6,10)$, we needed to determine whether or not these lesions were derived from the conceptus, that is the gestational type. Accordingly, we performed the polymerase chain reaction (PCR) to detect the SRY gene in the needle-biopsied sample. Briefly, DNA was extracted from formalin-fixed 4-tissue sections using TaKaRa DEXPAT Easy (Takara Co. Kyoto, Japan). Using SRY primers (5'-CAGTGTGAAACGGGAGAAAACAGT-3'; 5'-TATAAG TATCGACCTCGTCGGAAG-3') (11) and GAPDH primers (5'-GGAGCGAGATCCCTCCAAAAT-3'; 5'-GGCTGTTGT CATACTTCTCATGG-3') (12), both genes were amplified in 40 cycles. The SRY gene was successfully detected (Fig. 2D), indicating that this DNA contained Y-chromosome-specific genes.

Informed consent for the use of these tissues in this study was obtained from the patient. Analysis of these samples was approved by the Ethics Committee of the Kanazawa University Graduate School of Medical Sciences.

\section{Discussion}

In this case, the malignancy-suspected solitary lesion that can be responsible for the elevation of hCG was also observed in the right lung by enhanced CT and PET-CT $(13,14)$. In addition, since the morphological characterization of the renal lesion by ultrasound examination was compatible with that of renal cell carcinoma, we had to rule out the possibility of independent renal carcinoma. Consequently, we tried to biopsy the renal lesion with a fine needle technique. Although the amount of the obtained tissue sample was small, it contained the malignant lesion, and we successfully achieved a final pathological diagnosis of choriocarcinoma. However, the lesion sample was very limited, making it difficult to extract non-contaminated choriocarcinoma-derived DNA samples that were sufficient for the standard analysis of gene polymorphism.

Fortunately, according to the history, this patient had given birth to two male babies in the previous pregnancies, along with one artificial abortion. Furthermore, although the precise amount and purity were unclear, we could prepare DNA samples of choriocarcinoma from the formalin-fixed tissue slices. Consequently, we applied the above method and detected a paternal SRY gene consensus, leading to the conclusion that this case was gestational choriocarcinoma. Both renal and right lung lesion were evaluated as metastases of gestational choriocarcinoma.

Although differences have been reported in the chemotherapy response, genetic origin and prognosis, gestational and non-gestational choriocarcinoma exhibit similar morphological pattern, histopathological classification and biochemical markers $(4,15,16)$. Even with multidrug chemotherapy, a large number of patients with non-gestational choriocarcinoma died from the disease (16). In non-gestational choriocarcinoma, surgery and treatment with multiple chemotherapy agents are indicated. Therefore, distinguishing these two entities is very important (4).

The SRY gene is one of the Y-chromosome-specific genes. Therefore, when the SRY gene is detected in DNA samples extracted from choriocarcinoma tissues, we can safely conclude that this lesion is derived from the conceptus, except for the rare cases of chromosome chimera induced by bone transplantation, twin pregnancy, etc. In this context, fluorescence in situ hybridization (FISH) using centromere probe of Y chromosome could be used for this case. However, the weak point of these methods is that they cannot be applied to patients with a history of female delivery and sex-non-determined abortions. Accordingly, the negative detection of the SRY gene cannot lead to a definitive conclusion.

In conclusion, this is the first report that the detection of the SRY gene by PCR is clinically available to diagnose extragenital gestational choriocarcinoma. Since PCR is a more convenient method than gene polymorphism analysis, this method is one of the candidates for alternative techniques when the sample is limited and marked contamination of maternal DNA is expected (17).

\section{Acknowledgements}

The present study was supported in part by Grants-in-Aid for Scientific Research (no. 15K10708).

\section{References}

1. Vereczkey I, Csernák E, Olasz J, Küronya Z, Szentirmay Z and Tóth E: Renal choriocarcinoma: Gestational or germ cell origin? Int J Surg Pathol 20: 623-628, 2012.

2. Koyanagi T, Fujiwara H, Usui H, Ariga H, Machida S, Takei Y, Saga Y, Shozu M, Fukushima N, Tóth E, et al: Ovarian nongestational choriocarcinoma and associated adenocarcinoma with the same germ cell origin determined by a molecular genetic approach: A case report. Pathol Int 66: 529-534, 2016.

3. Tempfer C, Horn LC, Ackermann S, Beckmann MW, Dittrich R, Einenkel J, Gunthert A, Haase H, Kratzsch J, Kreissl MC, et al: Gestational and non-gestational trophoblastic disease. guideline of the DGGG, OEGGG and SGGG (S2k Level, AWMF registry No. 032/049, december 2015). Geburtshilfe Frauenheilkd 76: 134-144, 2016.

4. Mello JB, Ramos Cirilo PD, Michelin OC, Custódio Domingues MA, Cunha Rudge MV, Rogatto SR and Maestá I: Genomic profile in gestational and non-gestational choriocarcinomas. Placenta 50: 8-15, 2017.

5. Fisher RA, Newlands ES, Jeffreys AJ, Boxer GM, Begent RH, Rustin GJ and Bagshawe KD: Gestational and nongestational trophoblastic tumors distinguished by DNA analysis. Cancer 69: 839-845, 1992.

6. Wang Y, Yang Y, Teng F, Zhang H and Xue F: Pure nongestational uterine choriocarcinoma in a postmenopausal Chinese woman confirmed with short tandem repeat analysis. Am J Obstet Gynecol 211: e1-e3, 2014. 
7. Imamura Y, Tashiro H, Saito F, Takaishi K, Ohba T, Fukunaga M and Katabuchi H: Choriocarcinoma coexisting with epithelioid trophoblastic tumor of the uterine horn. Gynecol Oncol Rep 14: 31-33, 2015.

8. Wang Q, Guo C, Zou L, Wang Y, Song X, Ma Y and Liu A Clinicopathological analysis of non-gestational ovarian choriocarcinoma: Report of two cases and review of the literature. Oncol Lett 11: 2599-2604, 2016.

9. Yamamoto E, Niimi K, Shinjo K, Yamamoto T, Fukunaga M and Kikkawa F: Identification of causative pregnancy of gestational trophoblastic neoplasia diagnosed during pregnancy by short tandem repeat analysis. Gynecol Oncol Case Rep 9: 3-6, 2014.

10. Zhao J, Xiang Y, Wan XR, Feng FZ, Cui QC and Yang XY: Molecular genetic analyses of choriocarcinoma. Placenta 30: 816-820, 2009.

11. Kuroki M, Okayama A, Nakamura S, Sasaki T, Murai K, Shiba R, Shinohara M and Tsubouchi H: Detection of maternal-fetal microchimerism in the inflammatory lesions of patients with Sjogren's syndrome. Ann Rheum Dis 61: 1041-1046, 2002.

12. Yang G, Zhou X, Chen T, Deng Y, Yu D, Pan S and Song Y: Hydroxysafflor yellow A inhibits lipopolysaccharide-induced proliferation and migration of vascular smooth muscle cells via Toll-like receptor-4 pathway. Int J Clin Exp Med 8: 5295-5302, 2015.
13. Brown J, Naumann RW, Seckl MJ and Schink J: 15 years of progress in gestational trophoblastic disease: Scoring, standardization and salvage. Gynecol Oncol 144: 200-207, 2017.

14. Mangili G, Lorusso D, Brown J, Pfisterer J, Massuger L, Vaughan M, Ngan HY, Golfier F, Sekharan PK, Charry RC, et al: Trophoblastic disease review for diagnosis and management: A joint report from the international society for the study of trophoblastic disease, european organisation for the treatment of trophoblastic disease and the gynecologic cancer intergroup. Int J Gynecol Cancer 24 (suppl 3): S109-S116, 2014.

15. Cheung AN, Zhang HJ, Xue WC and Siu MK: Pathogenesis of choriocarcinoma: Clinical, genetic and stem cell perspectives. Future Oncol 5: 217-231, 2009.

16. Newlands ES: The management of recurrent and drug-resistant gestational trophoblastic neoplasia (GTN). Best Pract Res Clin Obstet Gynaecol 17: 905-923, 2003.

17. Robino C, Barilaro MR, Gino S, Chiarle R, Palestro G and Torre C: Incestuous paternity detected by STR-typing of chorionic villi isolated from archival formalin-fixed paraffin-embedded abortion material using laser microdissection. J Forensic Sci 51: 90-92, 2006. 